Original Article

\title{
ACUTE POST COMPLICATIONS IN STROKE PATIENTS VISITING A TERTIARY TEACHING HOSPITAL
}

\begin{abstract}
SPURTHI T. ${ }^{*}{ }^{*}$, REKHA RANI K. ${ }^{2}$, NAVYA Y. ${ }^{3}$, SWATHI D. ${ }^{4}$, RAMESH KUMAR P. ${ }^{4}$
${ }^{* 1}$ Department of Pharmacy Practice, Creative Educational Society's College of Pharmacy, N. H.7, Chinnatekur, Kurnool, Andhra Pradesh, 2,3Department of Pharmaceutics, Creative Educational Society's College of Pharmacy, N. H.7, Chinnatekur, Kurnool, Andhra Pradesh, ${ }^{4}$ Pharm. D Student, Department of Pharmacy Practice, Creative Educational Society's College of Pharmacy, N. H.7, Chinnatekur, Kurnool, Andhra Pradesh Email: t.spurthireddy@gmail.com
\end{abstract}

Received: 22 Oct 2017 Revised and Accepted: 08 Mar 2018

\section{ABSTRACT}

Objective: The study was focused on assessing the incidence of stroke and their association with types of the risk factor, with an emphasis on acute post complications and their symptomatic management for early detection.

Methods: A prospective observational study was carried out on stroke patients visiting a medicine department of a tertiary hospital, Andhra Pradesh, India from August 2017 to November 2017. Patient's demographics and lab data was collected for analysis.

Results: A total of 110 patients participated in the study. Among them high incidence is males (69\%), 61-80yrs (48\%), with 2 risk factors (35\%) among which age $(67 \%)$ and hypertension $(66 \%)$ were related to the high degree of prevalence. $47 \%$ of the study population were identified with one complication, among which seizures account for $38 \%$ of patients. All the complications associated with the condition were treated with drug classes, in which anti-epileptic drugs (AEDs) were the mainstay in the management of epilepsy.

Conclusion: Brain edema and seizure attack were the most accountable complications identified in the study population. The early detection of these problems can improve the stroke outcomes and can reduce the mortality or disability rate.

Keywords: Epilepsy, Hypertension, Post-complications, Stroke

(C) 2018 The Authors. Published by Innovare Academic Sciences Pvt Ltd. This is an open access article under the CC BY license (http://creativecommons.org/licenses/by/4.0/) DOI: http://dx.doi.org/10.22159/ijpps.2018v10i4.24396

\section{INTRODUCTION}

Apoplexy, the word used by Hippocrates, who is considered as the father of medicine now commonly known as a stroke, which is defined as a syndrome with several pathophysiologies involved. According to the World Health Organization (WHO) it is a condition "characterized by rapidly developing clinical symptoms and/or signs of focal, and at times global, loss of cerebral function, with symptoms lasting more than $24 \mathrm{~h}$ leading to death with no apparent cause other than that of vascular origin" [1].

Globally cardiovascular diseases are considered to be the first commonest cause of mortality among which stroke occupies the second place [2]. As per India stroke Factsheet updated in 2012, the age-adjusted estimates prevalence rate ranges between $84 / 100,000$ and $262 / 100,000$ in rural and between 334/100,000 and $424 / 100,000$ in urban areas [3]. Reports show a decline in death rates in past decades still it holds approximately $20 \%$, ranging from $15 \%$ to $58 \%$ depending on stroke subtype. Based on risk factors and pathophysiological changes, stroke is mainly classified as Ischemic and hemorrhagic type. Both share a crucial role in the extent and site of brain damage that determines the pre and post-stroke complications, therapeutic interventions and socioeconomic burden on patients. In addition to the initial neuronal damage resulting in functional, cognitive, and sensory deficits associated with the disease, patients are also at high risk of developing a wide range of medical complications, which account for $40 \%$ to $96 \%$ [4], involving both short-term and long-term complications: pneumonia, urinary tract infection (UTI), pressure ulcer, falls, venous thromboembolism, seizures, osteoporosis and central pain states [1].

Recent studies showed an incidence rate of 119-145/100,000 in India [3]. High chance of recurrence in stroke survivors, post-stroke complication risk and long-term rehabilitation due to diseaseassociated disability and economic burden on patient demands for its early identification. So the objective of this study is to focus on the incidence of these complications whose identification helps in early recognition, prevention and management of the condition and improving the patient care.

\section{MATERIALS AND METHODS}

A prospective observational study for assessing the demographic parameters, risk factors associated and post-complication of stroke patients was conducted in the medicine department of a tertiary care teaching hospital for a period of 6 mo from August 2017 to November 2017 in Kurnool district, Andhra Pradesh.

\section{Materials}

Consent form for patients, Data entry form 1 for demographic details and Data entry form 2 for listing the post-stroke complications with respective treatment chart.

\section{Inclusion criteria}

The patients who meet the following criteria was enrolled where, Inclusion criteria were patients aged $\geq 18 \mathrm{y}$ of both genders, who had provided a consent to participate in the study.

\section{Exclusion criteria}

Patients with diseases like psychiatry, cancer, pregnant and nursing mothers were excluded.

\section{Study method}

The details of cases found in the medicine department, including patient name, age, sex, past medical history and other relevant information were collected. The collected prescription was entered into the Microsoft Office Excel sheet according to their age, gender; therapeutic category and mean percentage were calculated.

\section{Ethical approval}

Consent from all the patients was taken in respective form and Ethical approval was taken with a no. 9 from Viswabharathi Medical College. 


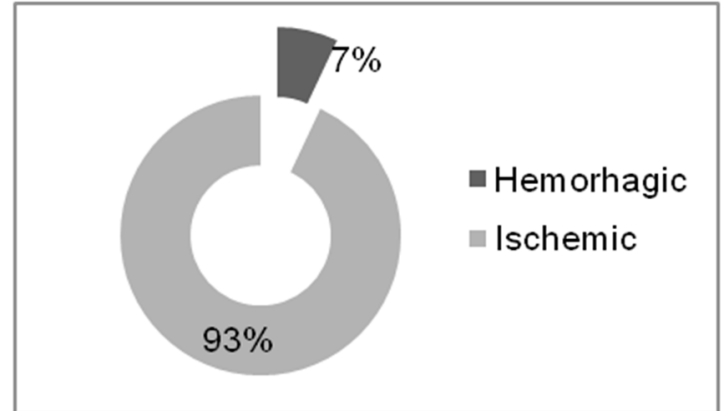

Fig. 1: Percentage of the study population diagnosed with ischemic and hemorrhagic stroke

\section{RESULTS}

A total of 110 patients who are diagnosed with any one type of stroke are recruited for the study after a proper consent was taken. Out of them, the highest incidence is ischemic stroke affecting 102 (93\%) patients followed by $8(7 \%)$ patients with hemorrhagic type represented in Error! Reference source not found.. Among Ischemic stroke patients, most of them are males $70(69 \%)$ compared to females 32 (31\%) as shown in Error! Reference source not found.. It was found that all the hemorrhagic patients are found to be males.

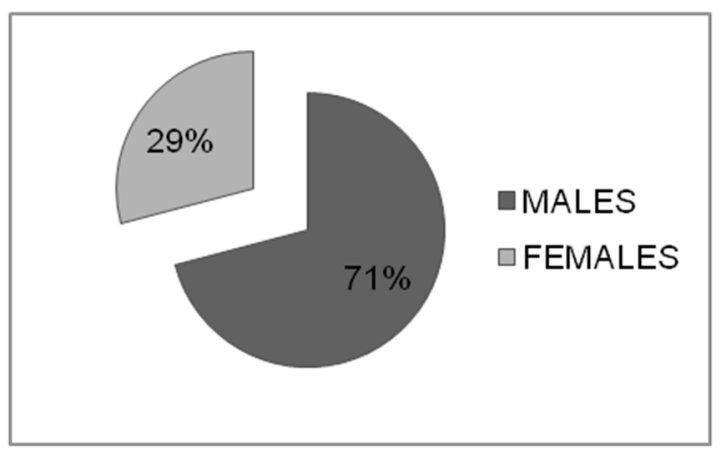

Fig. 2: Gender distribution among patients suffering from ischemic stroke

The patients based on their demographic data were categorized into different age groups and among them, most of the patients were identified under 61-80 y range i.e., 53(48\%). Age groups and patients distributed among are mentioned in Error! Reference source not found.

Table 1: Age distribution in stroke patients

\begin{tabular}{lll}
\hline Age range & Sum (n=110) & \% \\
\hline $0-20$ & 0 & 0 \\
$21-40$ & 8 & 7 \\
$41-60$ & 45 & 41 \\
$61-80$ & 53 & 48 \\
$81-100$ & 4 & 4 \\
\hline
\end{tabular}

In the study population nearly $35 \%$ of them were found with 2 risk factors, followed by $25 \%$ by 3 and $14 \%>3$ risk issues associated. Only $5 \%$ of them showed nil risk factors, as depicted in Error!
Reference source not found. Among them, age (67\%) and hypertension $(66 \%)$ was related to the high degree of prevalence and other risks in patients are shown in Table 2.

Table 2: Number of risk factors

\begin{tabular}{lll}
\hline Risk factor & Patient number & Percentage \\
\hline 0 & 6 & $5 \%$ \\
1 & 23 & $21 \%$ \\
2 & 39 & $35 \%$ \\
3 & 27 & $25 \%$ \\
$>3$ & 15 & $14 \%$ \\
\hline
\end{tabular}

The patients are treated with the different class of drugs among which anti-platelets $88(91.16 \%)$ accounts the highest percentage and nitrates
$6(0.62 \%)$ is the least prescribed. The remaining classes of drugs and their percentage of usage are mentioned in following table 3.

Table 2: Type of risk and patient percentage

\begin{tabular}{lll}
\hline Risk factor & Patient number & Percentage \\
\hline Age & 74 & $67 \%$ \\
Alcohol & 24 & $22 \%$ \\
Cigarette smoking & 13 & $12 \%$ \\
Diabetes mellitus & 40 & $36 \%$ \\
Hypertension & 73 & $66 \%$ \\
Cardiac disease & 12 & $11 \%$ \\
Parkinson's disease & 2 & $2 \%$ \\
\hline
\end{tabular}

It was noted that $47 \%$ of the study population were identified with one complication, among which seizures account for $38 \%$ of patients. $45 \%$ of patients developed brain edema, confirmed by
CT scans within 2-5 d of their disease onset. The individual percentages of patients with the complications are mentioned in Table 3 and Table 4. 
Table 3: Patients with stroke complication

\begin{tabular}{lll}
\hline Number of complication & Patient number & Percentage \\
\hline 0 & 14 & $13 \%$ \\
1 & 52 & $47 \%$ \\
2 & 36 & $33 \%$ \\
3 & $5 \%$ & $5 \%$ \\
\hline 3 & 2 & $2 \%$ \\
\hline
\end{tabular}

Table 4: Type of complication and their percentage

\begin{tabular}{lll}
\hline Complication type & Patient number & Percentage \\
\hline Brain edema & 50 & 45.5 \\
Seizures & 35 & 31.8 \\
DVT & 26 & 23.6 \\
Depression and anxiety & 12 & 10.9 \\
Limb pain & 9 & 8.2 \\
Urinary tract infection & 4 & 3.6 \\
Chest infections & 4 & 3.6 \\
\hline
\end{tabular}

All the complications associated with the condition were treated with drug classes in the study population. Edema, due to the pathophysiological changes of ischemia was controlled by using an osmotic diuretic (mannitol) in all 50 patients (100\%). In all age groups, anti-epileptic drugs (AEDs) were the mainstay in the management of epilepsy. AEDs accounted for nearly $75 \%$ of poststroke seizure therapy, followed by benzodiazepines i.e., clonazepam (25\%). The different complications and their respective management options, by utilizing the varied class of drugs are listed in the following Table 5 and AEDs= Anti-Epileptic drugs; BZDs= Benzodiazepines; $\quad$ CTX=Ceftriaxine; $\quad$ MEM=Meropenam; NSAIDs=Non-steroidal anti-inflammatory drugs; OXA=0floxacin; SSRIs=Seratonin selective re-uptake inhibitors; TCAs=Tricyclic antidepressants.

Table 5: Drug utilization in the therapy of post-stroke complications

\begin{tabular}{|c|c|c|c|}
\hline Complication & Class of drugs used & No of patients & Percentage \\
\hline \multirow[t]{2}{*}{ Seizures } & BZDs & 9 & 25 \\
\hline & AEDs & 27 & 75 \\
\hline \multirow[t]{3}{*}{ Limb pain } & NSAIDS & 16 & 61.5 \\
\hline & Tramadol & 5 & 19.2 \\
\hline & Muscle Relaxants & 5 & 19.2 \\
\hline \multirow[t]{2}{*}{ DVT } & LMWHs & 24 & 82.8 \\
\hline & Others & 5 & 17.2 \\
\hline \multirow[t]{3}{*}{ Depression and anxiety } & BZD & 8 & 61.5 \\
\hline & SSRIs & 4 & 30.8 \\
\hline & TCAs & 1 & 7.7 \\
\hline UTI & Fluoroquinolones (OXA) & 4 & 100 \\
\hline \multirow[t]{3}{*}{ Chest infections } & Carbepenems (MEM) & 2 & 40 \\
\hline & Fluroquinolones (MXF) & 2 & 40 \\
\hline & Cephalosporins (CTX) & 1 & 20 \\
\hline
\end{tabular}

AEDs= Anti-Epileptic drugs; BZDs= Benzodiazepines; CTX=Ceftriaxine; MEM=Meropenam; NSAIDs=Non-steroidal anti-inflammatory drugs; OXA=Ofloxacin; SSRIs=Seratonin selective re-uptake inhibitors; TCAs=Tricyclic anti-depressants.

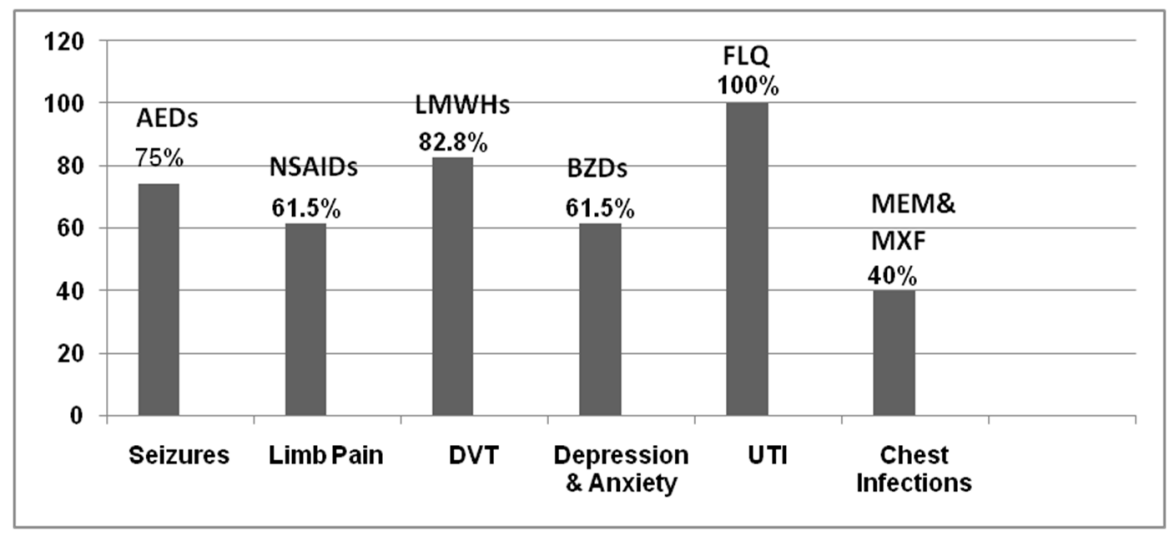

Fig. 3: Highly prescribed drug class in various post-stroke complications 


\section{DISCUSSION}

Many studies on the incidence of stroke reported the predominance of the ischemic type over hemorrhagic, in concordance with our study results were $93 \%$ of the patients belong to that group [5-7].

The demographic parameters of the study populations show a dominance of male gender (71\%), of age group 61-80 y range i.e., (48\%). Similar reports were shown in other Studies [5-8].

In the study population, nearly $35 \%$ of them were found with 2 risk factors, similar to another study by Shrestha [7]. A study by Vaidya detailed that hypertension is one of the most common risk factors associated with stroke patients, in similarity with our results, showing $66 \%$ of the population with hypertension [5]. A retrospective study by another author also reported that $62 \%$ of their stroke patients had hypertension as the risk factor [9].

Various medical, neurological and psychological complications are allied to stroke after the acute attack. The identification of such complications in the first days of effect helps to notice the early preventability with a high degree of functional outcome. In our study, high incidence of patients was with one complication i.e., $47 \%$, in similarity with Karen c. Johnston $[10,1]$. A population-based study in Sweden found that patients over 60 y of age, $45 \%$ of seizures were secondary to stroke and associated with a 23-35-fold increase in the incidence of seizure. In our study, most of the patients showed seizure symptom during a stroke attack. In earlier studies, a highly variable, ranging from a low of $7.7 \%$ to a high of $42.8 \%$ in the incidence of seizures were noted, but the recent study series shows fewer variants with average $10 \%$ risk of seizures within 9-10 y after stroke [11]. All the other complications were treated as per their standard guidelines for symptomatic relief.

\section{CONCLUSION}

Thus the correct identification of the risk factors associated with the stroke patients prior; help us to bring down the cost burden along with improvement in the quality of life effectively. This study turned out to be similar to many other studies in different countries implementing the need for patient-specific risk correction by using standard therapeutic guidelines, for effective patient-centred care. This study is mainly limited to less number of sample in a single center, hence further research in assessing the risk factors and post complications in stroke patients, paving for a significant disease management outcomes.

\section{ACKNOWLEDGMENT}

The authors humbly acknowledge the contribution and help by patients, principal and management of Department of Pharmacy Practice, CES College of Pharmacy, Kurnool, A. P. We duly express our thanks to the institution-affiliated teaching hospital administration for their support and cooperation in completing research work.

\section{AUTHORS CONTRIBUTIONS}

Spurthi T completed my post-graduation (M. Pharm in Pharmacy practice) from Manipal College of Pharmaceutical Sciences, Manipal. Currently working as an assistant professor (Department of pharmacy practice) in CES College of Pharmacy, Kurnool, Andhra Pradesh.

\section{Co-author}

Ms. Rekha rani K and Mrs. Navya Y helped for the research activity and Rani P, along with Kusuma Kumari worked in collecting the data from the hospital. As co-authors regarding this paper, all of them provided their knowledge and time from beginning to end of the work.

\section{CONFLICT OF INTERESTS}

\section{Declared none}

\section{REFERENCES}

1. Annette I, Grethe A, Heidi HH, Marie LS, Soren PJ. Medical complications in patients with stroke: data validity in a stroke registry and a hospital discharge registry. Clin Epidemiol 2010;2:5-13.

2. WHO. 2017. Available from: http://www.who.int/ mediacentre/factsheets/fs310/en/:Top 10 causes of death worldwide. [Last accessed 21 Nov 2017]

3. Jeyaraj DP, Paulin S. Stroke epidemiology and stroke care services in India. J Stroke 2013;15:128-34.

4. Jose CN, Ester B, Nijasri S, Hui MC, Shan JR, Yi NH, et al. Complication of acute stroke: a study in ten Asian countries. Neurol Asia 2008;13:33-9.

5. Chirayu VV, Drusty KM. A retrospective study of clinical profile of stroke patients from GMERS Medical College and Hospital, Gandhinagar, Gujarat. Int J Clin Trials 2014;1:62-6.

6. Vinay Kumari, Meena Aggarwal, Achal Srivastava. A retrospective study to identify triggers or precipitators related to the onset of stroke. Nursing Midwifery Res J 2012;8:141-8.

7. Shrestha A, Shah DB, Koirala SR, Adhikari KR, Sapkota S, Regmi PR. Retrospective analysis of stroke and its risk factors at bir hospital. PMJN 2011;11:28-30.

8. Mohan DK, Nikhitha M, Dhananjaya M. A retrospective study of stroke in young adults from tertiary care hospital. Sch J App Med Sci 2013;1:506-10.

9. Indira Kumari N, Veera Raghavulu B. Risk factor assessment of stroke and its awareness among stroke survivors: a retrospective study. Int J Res Health Sci 2015;3:140-5.

10. Karen CJ, Jiang YL, Patrick DL, Sandra KH, Thomas EF, Robert $\mathrm{JA}$, et al. Medical and neurological complications of ischemic stroke experience from the RANTTAS trial. Stroke 1998;29:447-53.

11. Benny SK, Cathy Sila. Seizures in ischemic stroke. In: Mohamad Koubeissi, Amer Alshekhlee, Prachi Mehndiratta. editors. Seizures in Cerebrovascular Disorders-A clinical guide. New York: Springers; 2015. p. 17-30. 